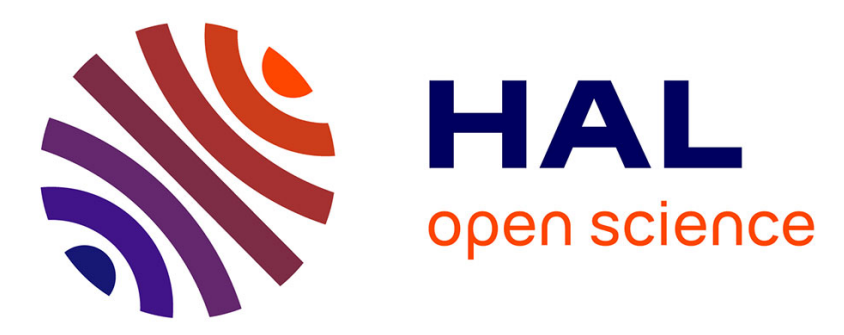

\title{
AN OPEN SOURCE REMOTE LABORATORY NETWORK BASED ON A READY TO USE SOLUTION: LABOREM
}

B. Letowski, C Lavayssière, B Larroque, Franck Luthon

\section{- To cite this version:}

B. Letowski, C Lavayssière, B Larroque, Franck Luthon. AN OPEN SOURCE REMOTE LABORATORY NETWORK BASED ON A READY TO USE SOLUTION: LABOREM. 12th Int. Conf. of Education, Research and Innovation (ICERI 2019), Nov 2019, Seville, Spain. pp.5726-5731. hal02463754

\section{HAL Id: hal-02463754 \\ https://cnrs.hal.science/hal-02463754}

Submitted on 1 Feb 2020

HAL is a multi-disciplinary open access archive for the deposit and dissemination of scientific research documents, whether they are published or not. The documents may come from teaching and research institutions in France or abroad, or from public or private research centers.
L'archive ouverte pluridisciplinaire HAL, est destinée au dépôt et à la diffusion de documents scientifiques de niveau recherche, publiés ou non, émanant des établissements d'enseignement et de recherche français ou étrangers, des laboratoires publics ou privés. 


\title{
AN OPEN SOURCE REMOTE LABORATORY NETWORK BASED ON A READY TO USE SOLUTION: LABOREM
}

\author{
B. Letowski, C. Lavayssière, B. Larroque, F. Luthon \\ Université de Pau et des Pays de l'Adour/E2S UPPA, IUT Bayonne Institute of Technology \\ (FRANCE)
}

\begin{abstract}
To answer to the widespread use of computers and internet, our project (Laborem) is to implement new tools for teachers and learners as remote laboratories, the objective is to increase the student motivation. A robotic arm, a modular motherboard and generic plugs are used by students to build their circuits. The learning objectives are to implement basic electronic circuit and to practice instruments use for test and measurement. Our objective is to offer an open source and low-cost e-lab to unite a community of remote laboratories. Accordingly, we have developed a software running on single-board computer like a Raspberry Pi with a solution based on a HTML web interface for the front-end and Python code for the back-end. It is now possible to run an automatic installation script and to switch between different acquisition equipment (oscilloscope, arbitrary function generator). For the hardware part, we have designed and realized a motherboard to access to 16 different electronic circuit which can be modified. Switches are implemented to activate and to deactivate components, also digital devices are inserted in the plugs like potentiometer controlled by I2C protocol. Finally, all the elements are integrated in a plastic box realized with a 3D printer. Future works are focused on increasing communication protocols (web services or BACnet/IP) and connecting various engineering education centers.
\end{abstract}

Keywords: e-learning, industrial engineering, lab work, student motivation, online education, virtual instruments, electronics, SCADA, network.

\section{INTRODUCTION}

Distance education is growing easier and faster with the widespread use of computers and internet. Moreover, it is noticed a diversification in post-secondary student profile. To answer this issue, it appears decisive to create new tools for teachers and learners as remote laboratories and game-like scenarios. Intermixing face-to-face and distant learning allows continuity between laboratory work and homework (remotely).

This paper deals with a remote laboratory project called Laborem which is dedicated to practical training in electronics. It addresses electronics engineering at undergraduate level. The practical laboratories deal with analog and digital electronics, such as filtering, instrumentation, diode/transistor characteristic, etc. These topics are widely taught everywhere in engineering degree at university; thus, we would like to share our work and unite a community around these teaching needs.

The Laborem main goal is to increase the student motivation. A robotic arm can be used by students to build their circuits. The learning objectives are to implement basic electronic circuit and to practice instruments use for test and measurement.

Our project has been evolving since 2009 [1]. It was originally developed with the proprietary LabVIEW software from National Instruments. However, we are now turning the project on an open source solution. As we previously presented in ICERI 2018 [2], the new open source solution has been developed to get rid of proprietary drivers and software. The aim is both to reduce cost and to ease the solution spreading.

Consequently, we have introduced a concept of modular motherboard and generic plug to answer all the electronics laboratory type. In addition, we are adapting all these electronics laboratory to be entirely remote controlled. For instance, students must perform remote measurements, such as temperature, variable resistor, various charge load or implement different filtering circuit. That is why they need controlled plugs to perform all the measurement and compare solutions.

In our opinion, creating a network of these remote laboratories can be very useful to share expensive experiments or equipment between engineering education training centers. The approach is inspired by the University Network of Interactive Labs (UNILabs) [3] and the previous VISIR project [4]. 
The actual Laborem diagram is presented in the Figure 1. The central element is the server on the Raspberry Pi which communicate with a camera, a robot and equipment. Furthermore, it selects the Device Under Test (DUT) among the 16 plugs available on the control and acquisition card (motherboard). At last, the server is hosted by the Raspberry Pi and students can work on the remote laboratory thanks to the Human Machine Interface (HMI) through internet.

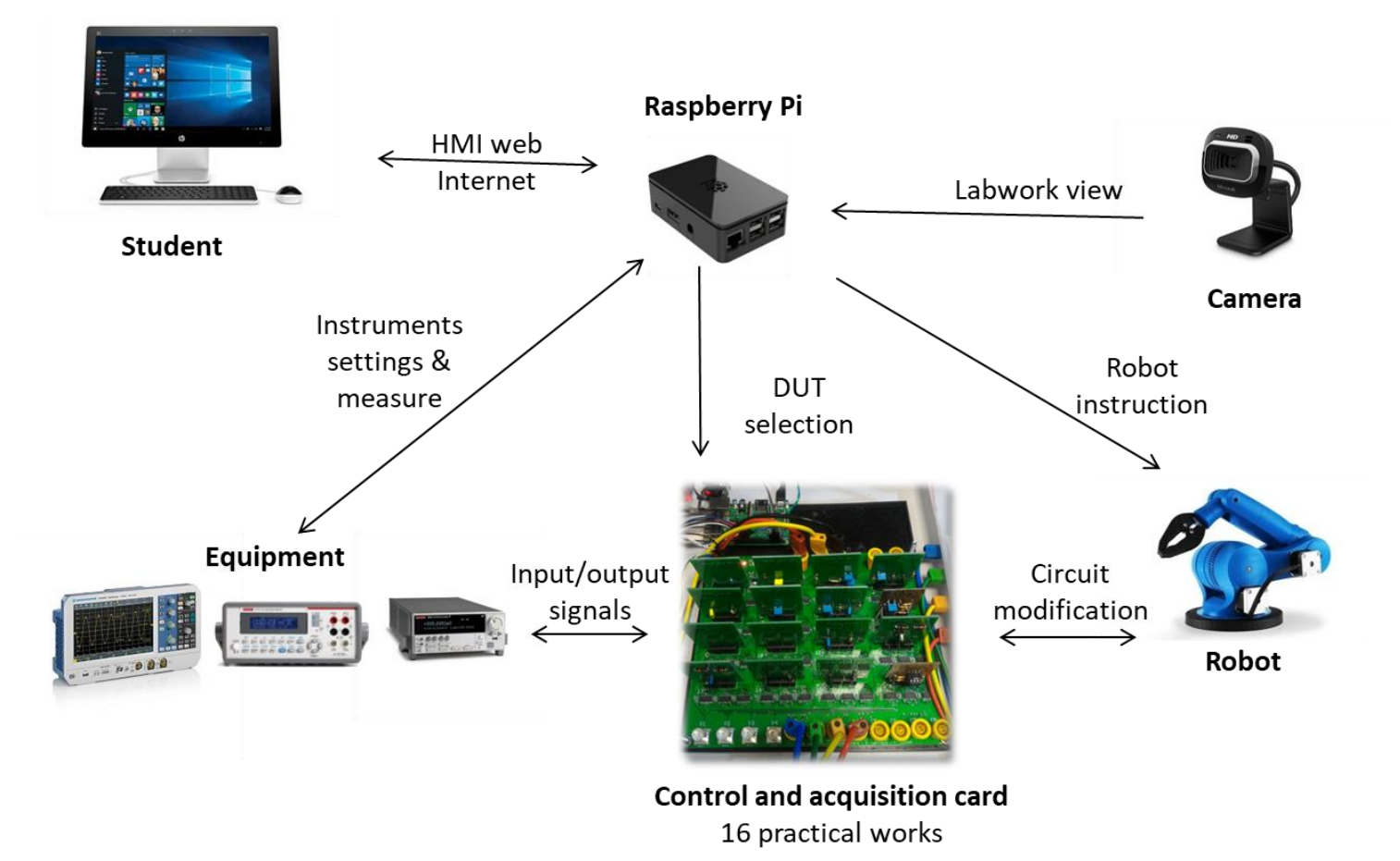

Figure 1 Laborem diagram

The paper is organized as follows: Section 2 presents software and network developments. Section 3 describes the implementation of an easy to use solution and newest remote-controlled work. Finally, Section 4 discusses conclusion and future of the Laborem network.

\section{SOFTWARE AND NETWORK METHODOLOGY}

\subsection{Raspberry Pi as a server}

The programing language used is Python. Django framework and PyScada [5] are also used in our development. Open source SCADA is a current research work in engineering as shown in [6], [7]. In our solution the server is embedded in a Raspberry Pi3. This solution is widely used in electronics as well as in remote laboratory [8], [9].

As using a database writing and reading all the time on a SD Card, it can damage it quickly [10] (around six months for our use), two options are offered: use an external hard drive (USB connected) instead of SD card, it is easy to set-up however slower than SD Card. This solution is acceptable for us however it increases the cost of the remote lab. The other solution is to copy our database in RAM at boot and to save it before shutting down the system. With only $1 \mathrm{~Gb}$ of RAM on the Raspberry Pi3, only $300 \mathrm{Mb}$ is still available for the database. It is not enough but with the new Raspberry Pi4 (available since June 2019) with $4 \mathrm{~Gb}$ of RAM this solution should work. In this case the access to the database is quicker than using an external hard drive or a SD Card but we must care to save the data in case of an unexpected shutdown. This solution is unstable and difficult to deal with.

The optimal solution to combine the advantages of both solutions lies in the combination of using the Raspberry Pi 4 (4 RAM) and HDD for periodical saving. 


\subsection{Laborem interface}

The new open source solution for electronics laboratories has been validated. For example, important functionalities have been created: performing spectrum analysis, exporting data and plots for evaluation. Accordingly, students can write down their measurement, plots and results on their practical works reports. The last developed $\mathrm{HMI}$ is illustrated in Figure 2.

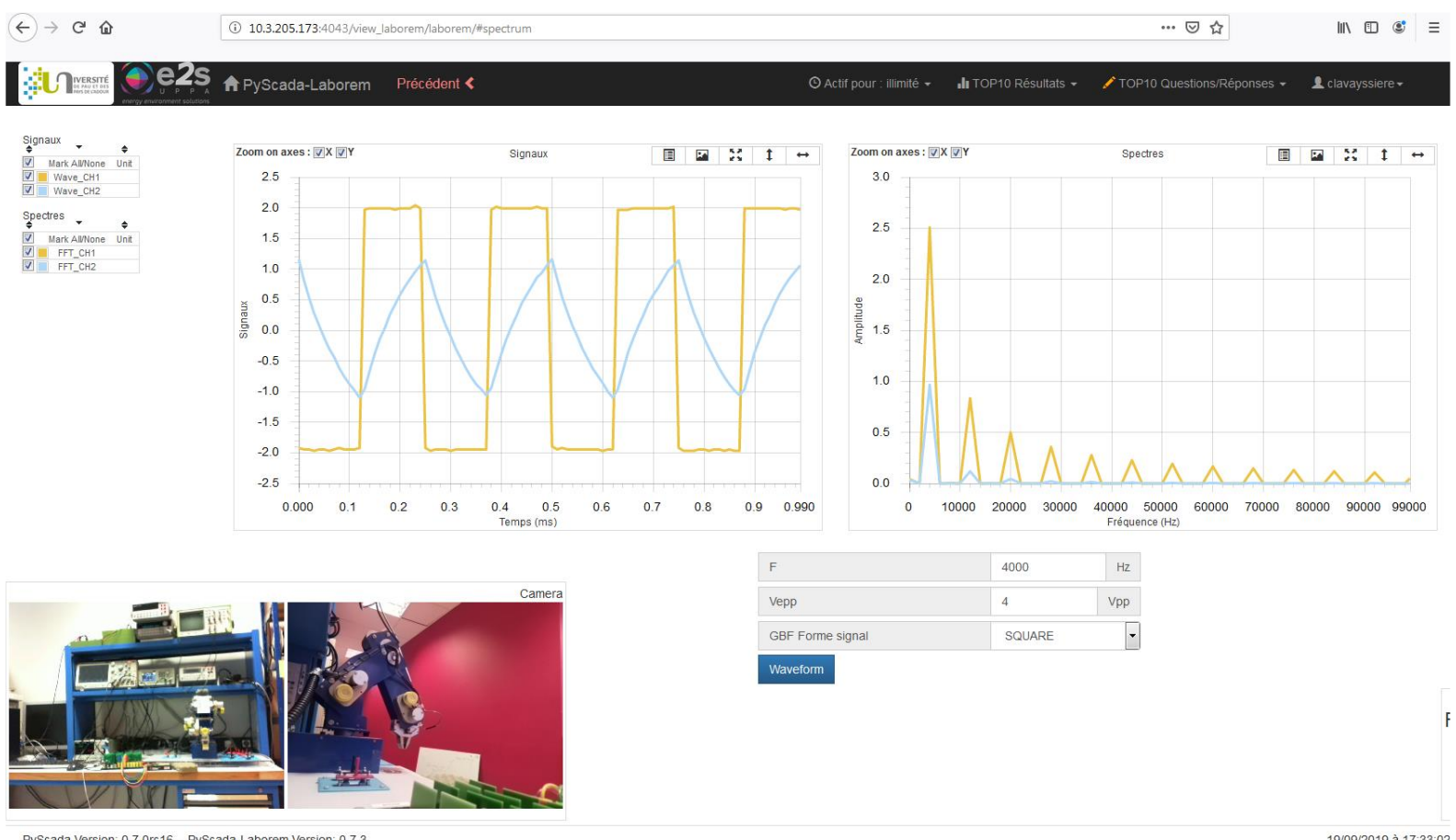

Figure 2 Spectrum analysis of an RC $1^{\text {st }}$ order filter with the Laborem HMI

The remote laboratory Laborem has an easy access with an IP address and it only needs a web browser, without any specific software on the "client side" according to requisites of remote laboratory [11].

\subsection{Install script}

With this functional and easy to deploy solution, current work focuses on a network of Laborem. The first step is to guaranty an open access to the software. The code is available for everyone on the GitHub platform ("PyScada-Laborem"). However, the PyScada based solution used different programming block and it could be uneasy to be correctly configured. To answer this issue, a script has been developed allowing manual or automatic installation therefore everyone can implement by himself a Laborem solution. The scheme available in Figure 3 describes the install script procedure.

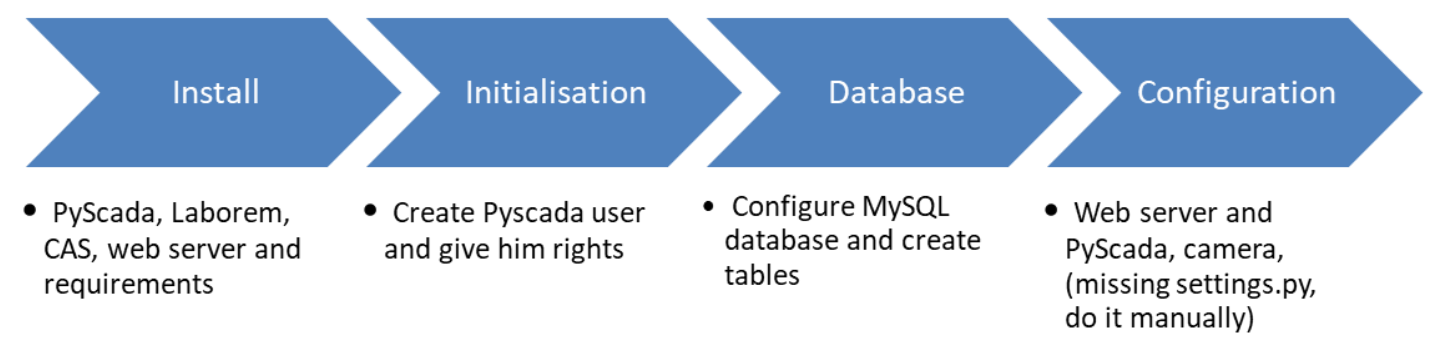

Figure 3 Install script description (where CAS means Central Authentication Service)

Furthermore, a library of measurement instruments is available (function generator, digital multimeter and oscilloscope) to guaranty compatibility with equipment available in laboratories. The teacher sets his workbench clearly using the Human Machine Interface. For instance, Tektronix and HP oscilloscopes are used and settled in the database. 


\section{THE REMOTE LABORATORY BOX}

\subsection{Active plugs}

Hardware development previously presented in ICERI 2018 has been validated. Moreover, to enhance the network spreading, all the designed and tested plugs are available online on GitHub ("Laborem-plugs") and OpenHardware.io. There are mainly passive and active filtering electronics circuits using operational amplifiers for now.

Our current work on plugs design is focused on two parts. Firstly, switches are implemented to activate and to deactivate components to modify the circuit. Secondly, digital components are inserted in the plugs like potentiometer controlled with $\mathrm{I} 2 \mathrm{C}$ protocol.

Indeed, instrumentation practical work needs this option of adjustable resistor, like Wheatstone bridge. Sensors and adjustable resistor are implemented to equilibrate the measure and can be controlled with switches. The thermal resistance is also operated to perform temperature measurement. The plug schematic is shown on Figure 4.

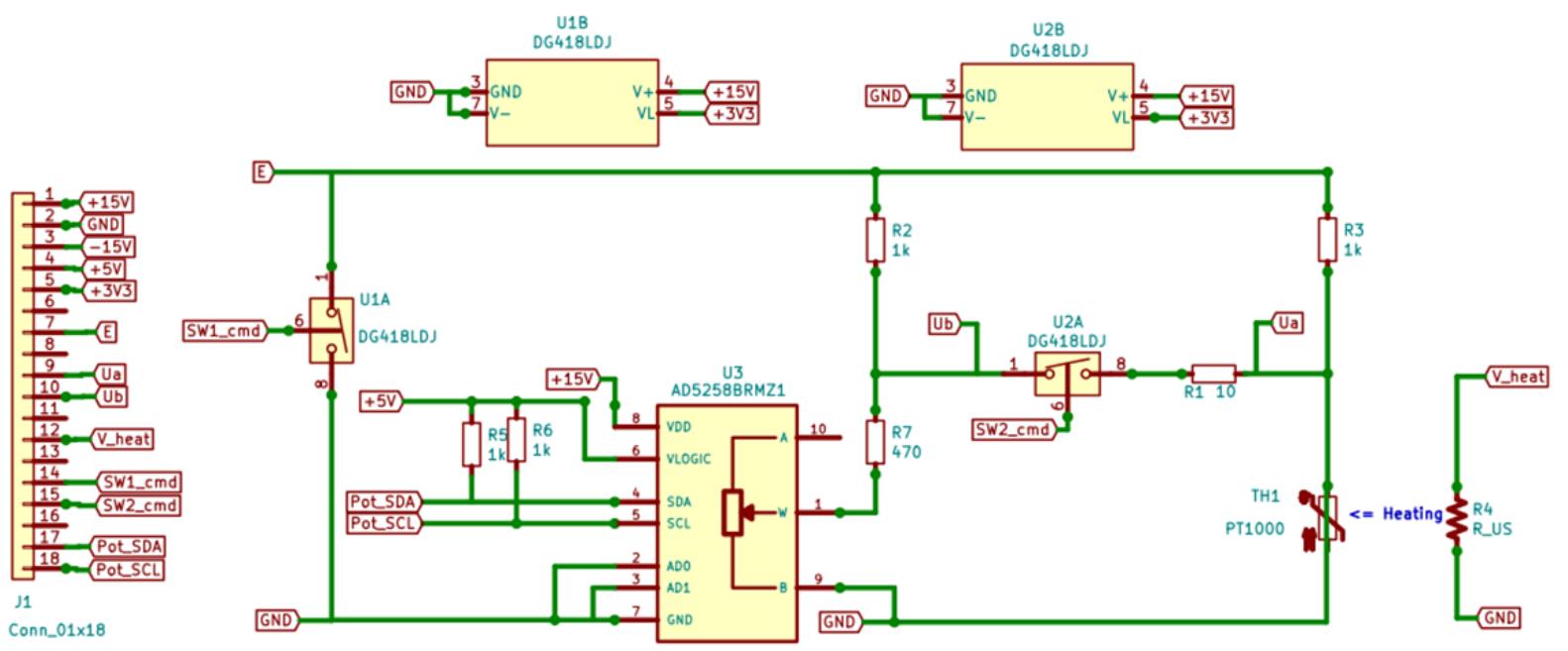

Figure 4 Schematics of the plug experimental work "Wheatstone bridge" with digital potentiometer and switches

The connector corresponds to the $\mathrm{PCl}$ Express male connector interconnecting plug and the motherboard. The first switch pilots the supply voltage which can be short circuited to perform bridge resistance measurement (Thevenin equivalent resistance). The second switch allows student to measure the output voltage when a charge is connected (R1).

The balance voltage $U_{A B}=0 \mathrm{~V}$ at room temperature is obtained through the digital potentiometer.

The experimental work is concluded with temperature measurement. The power resistor R4 is supplied with an analog voltage to heat the Resistance Temperature Detector (RTD). Then, the Wheatstone bridge temperature to voltage characteristic is performed by students. Finally, everything within the plug is remotely controlled. Students have the opportunity to enhance their practical skills on electronics instrumentation. 


\subsection{The stand-alone Laborem box}

Our stand-alone solution relies on the "Laborem Box" realized with a 3D printer in our laboratory. A plastic box has been designed to host all the Laborem devices: the motherboard, the single-board computer (SBC) embedding the server and a power supply card. The 3D view is shown in Figure 5.

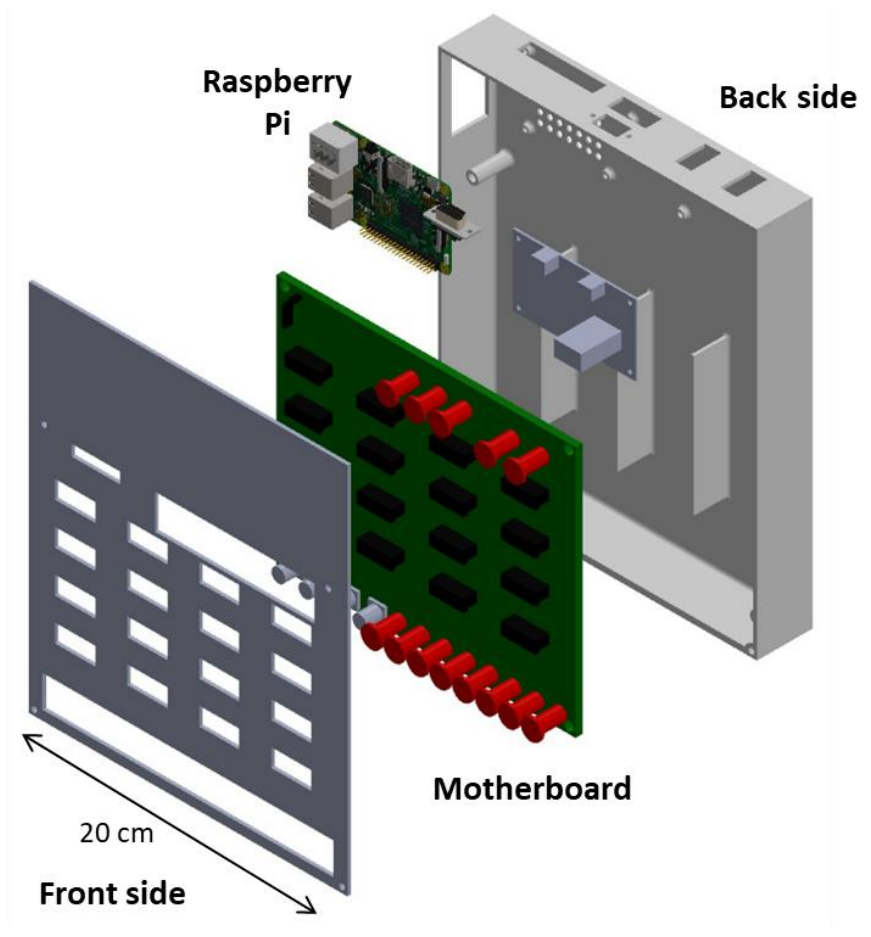

Figure $53 D$ view of the Laborem box designed on Solidworks

A supply card has been realized for the Raspberry and the motherboard. Moreover, a relay is controlled by the Raspberry to turn-off/on a multi-socket adaptor to power workbench instruments.

A new version of the motherboard will be designed with more Input / Output $(\mathrm{I} / \mathrm{O})$ connectors. More measurements $\mathrm{I} / \mathrm{O}$ are needed to interconnect all special characterization like four-probe measurement, as well to perform voltage and current measurement without modifying interconnections in the test bench.

\section{CONCLUSIONS}

The Laborem solution (software and box) has been already installed at the Technische Universität Berlin (TU Berlin). Two more installations are going to be deployed at the University Joseph KIZERBO in Ouagadougou in January 2020. New developments are conducted to increase communication protocols to web services (HTML) or BACnet/IP (automaton). This special feature will allow to work on energy monitoring of buildings based on electrical sensors exchange.

\section{ACKNOWLEDGEMENTS}

The authors would like to thank the staff of ISITE program E2S for financial support for the engineer fellowship of Camille Lavayssière. 


\section{REFERENCES}

[1] F. Luthon and B. Larroque, "LaboREM: A Remote Laboratory for Game-Like Training in Electronics," IEEE Transactions on Learning Technologies, vol. 8, no. 3, pp. 311-321, 2014.

[2] C. Lavayssière, B. Letowski, B. Larroque, and F. Luthon, "Easy applied sciences learning through open source remote laboratory," ICERI2018 Proceedings, pp. 2576-2583, 2018.

[3] "University Network of Interactive Laboratories." [Online]. Available: https://unilabs.dia.uned.es/. [Accessed: 15-Sep-2019].

[4] I. Gustavsson et al., "On Objectives of Instructional Laboratories, Individual Assessment, and Use of Collaborative Remote Laboratories," IEEE Transactions on Learning Technologies, vol. 2, no. 4, pp. 263-274, Oct. 2009.

[5] M. Schröder, "PyScada is an open source scada system that uses the Django framework as backend: trombastic/PyScada," 13-Sep-2018. [Online]. Available: https://github.com/trombastic/PyScada. [Accessed: 13-Sep-2018].

[6] D. F. Merchan, J. A. Peralta, A. Vazquez-Rodas, L. I. Minchala, and D. Astudillo-Salinas, "Open Source SCADA System for Advanced Monitoring of Industrial Processes," in 2017 International Conference on Information Systems and Computer Science (INCISCOS), Quito, 2017, pp. 160165.

[7] L. O. Aghenta and M. T. Iqbal, "Low-Cost, Open Source loT-Based SCADA System Design Using Thinger.IO and ESP32 Thing," Electronics, vol. 8, no. 8, p. 822, Aug. 2019.

[8] J. Bermúdez-Ortega, E. Besada-Portas, J. A. López-Orozco, J. A. Bonache-Seco, and J. M. de la Cruz, "Remote Web-based Control Laboratory for Mobile Devices based on EJsS, Raspberry Pi and Node.js," IFAC-PapersOnLine, vol. 48, no. 29, pp. 158-163, Jan. 2015.

[9] R. Reck and R. Sreenivas, "Developing an Affordable and Portable Control Systems Laboratory Kit with a Raspberry Pi," Electronics, vol. 5, no. 4, p. 36, Jul. 2016.

[10] "Kingston Flash Memory Guide." [Online]. Available: https://media.kingston.com/pdfs/MKF_283.1_Flash_Memory_Guide_EN.pdf. [Accessed: 17-Sep2019].

[11] S. D. Bencomo, "Control learning: present and future," IFAC Proceedings Volumes, vol. 35, no. 1, pp. 71-93, Jan. 2002. 